\title{
A Contrastive Analysis of Interpersonal Meaning in Chinese and English Public Service Advertisement
}

\author{
Xinzhuo Jiang ${ }^{1, a}$ and Jiang Liu ${ }^{2, b^{*}}$ \\ ${ }^{1}$ School of Foreign Languages, Yulin University, China, 719000 \\ ${ }^{2}$ School of Management, Yulin University, China, 719000 \\ a250883726@qq.com, ${ }^{b} 52186531 @ q q . c o m$ \\ * The Corresponding Author
}

Keywords: Public service advertisement; Interpersonal meaning; Evaluation

\begin{abstract}
Public service advertisement is a special kind of advertisement. It serves for the society without making any profits and aims to through various media to regulate and educate the public. This thesis compares Chinese and English public service advertisement from few aspects. Then draws a conclusion: different social-culture factors would have an effect on the realization of interpersonal meaning in Chinese and English public service advertisement.
\end{abstract}

\section{Introduction}

As a non-commercial advertisement, public service advertisement serves for the public interest, it aims to change the public's attitude or behaviors and then stimulate positive social change by education and awareness of significant social problems. Because of its special operation mechanism, public service advertisement is usually issued by the authority, thus, how to adjust the status and achieve effective communication between advertiser and audience becomes the main factor which decides success or failure of public service advertisement. The purpose of writing this thesis is to discuss how Interpersonal Meaning can be realized by comparing the Chinese and English public service advertisement.

\section{Interpersonal Meaning in Chinese and English Public Service Advertisement}

The introduction of public service advertisement. Public service advertisement is released on the media and serves the public interests for the non-profitable purpose. It transmits some ideas to arouse public awareness to social problem, and aims to regulate behaviors of the public. Public service advertisement plays an important role in advocating a correct value, promoting a good social morality and it originated early in foreign countries especially in some developed countries, such as the United States, France and other countries. The public service advertisement's enthusiastic supporters and sponsors are mainly national and international organizations such as World Health Organization (WHO), Organization for Economic Cooperation and Development (OECD) and so on.

In China, public service advertisement first appeared on television as "saving water" advertisement. Then, China Central Television founded the section of "Mass Media Informing Advertising" which broadcasts many public service advertisement in the prime-time, which makes the section of "public service advertising" begin to get more popular, and extends the field of media from television to road signs, newspapers, public places, etc. The content and form have become rich.

Interpersonal Meaning. Language is used to express the attitude of speaker and the influence on behaviors or the reaction of the hearer. The speaker can participate in the speech event, and makes himself have an interaction with the hearer, and shows how expedient is intended to be taken "the expression of speaker's comment, attitude and evaluation, and also the relation which the speaker sets up between himself and the listener-particularly the communication role that speaker adopts, of informing, greeting, persuading, questioning and the like" (Halliday, 1978: 57). The 
Interpersonal meaning deals with the dynamic relationship between the speaker and the listener. In interpersonal systems, mood and modality are two important representations.

In the western countries, many linguists devote themselves to studying interpersonal meaning of a language. Halliday is a typical one among these linguists. Durey also devotes himself to the research on the role of the functional triad in the portrayal of characters. These studies are mainly associated with the study of discourse structures, discourse resources and authorial attitudes.

In China, The studies of interpersonal meaning have become more popular. Compared with Ideational Meaning and Textual Meaning, Interpersonal Meaning has not gained enough attention. In recent years, Huang Guowen (2002) devotes himself to analyzing the interpersonal meaning in English translations. Li Zhanzi (2002) analyzes Interpersonal Meaning of autobiography genre by adopting functional grammar approach as her theoretical framework. Liu Ying (2004) also makes an analysis of interpersonal meaning in the texts of bank brochures.

\section{A Contrastive Analysis of Interpersonal Meaning of Chinese and English Public Service Advertisement}

A Contrastive Analysis of Modality in Chinese and English Public Service Advertisement. Modality is a way to transmit interpersonal meaning. It can be regarded as "comment" or "attitude" and express the speaker's judgment of probability, typicality, obligation, significant or tendencies related with speaking. Through modality the speaker can express one's opinion or attitude about what he says towards the truth.

The modality's realizations are modal operators, modal adjuncts, the expanded predicator and nominal equivalents. One of important realizations of the interpersonal meaning is modal operators. Ordinarily, modal operators can be classified into three fundamental values: high, median and low.

High value modal is used to show audience's strong commitment and operators appear infrequently in both Chinese and English public service advertisement. In Chinese contexts, there are modal verbs such as “应该”, “必须”, “得”.While in English contexts, there are modal verbs such as "need", "must", "have to". For example: "Animals are humans' friends. We should love and protect them." From the example, "should" is used to show the audience's high commitment to the proposition and show an obligation while they are dealing with a proposal of protecting the animals.

In Chinese and English public service advertisement, median value modal operators appear very frequently, especially in Chinese public service advertisement. In Chinese contexts, there are modal such as “将”, “要”, while in English contexts, median value modal verbs used frequently are “will”, "would", "should". For example: "With the love, they will improve more courage to struggle with the disease." From the example, we can see that median value modal operators "will" appear in the English contexts, it indicate a strong probability and show a prediction. By using "will", the advertisers show a confidence in the realization of the proposition.

In public service advertisement, low value modal refers to the advertiser's low commitment. Both in Chinese and English public service advertisement, a large number of low-value modal are found. In English contexts, it includes "can", "could", "might" and so on, while in Chinese contexts, “能够”, “可以”are included. For example: “You may not have noticed, but fish have gradually been getting smaller and smaller." From the example, by using "may", the advertisers mitigate their statement to increase their reliability which actually reduce the strength of assertion and convey the politeness to the audience.

A contrastive analysis of person in Chinese and English public service advertisement. In advertisement discourse, between the advertiser and the audience, personal pronouns and their possessive forms play an important role in establishing a relation. The advertiser often uses such pronouns as "you", "your", "we" and "our" to build a dialogue atmosphere with the audience.

Personal pronouns play important roles in traditional grammar. On the basis of the traditional grammar, there are three grammatical persons in English: first person (I / we) involves the speaker; the second person (you) involves the speaker, namely, the person is talking to; the third person (he/ she/ it/ they)is referring someone or something. 
In Chinese public service advertisement, the first personal pronouns refer to “我”, “我们”听““咱 们”. In English public service advertisement, there are "I" and "we". For example: "Our Earth, Our Future, Just Save It." In the example, "our" refers to both advertisers and the audience.

In Chinese public service advertisement, the second personal pronouns refer to “你”, “你们”. In English public service advertisement, there are "you" and "your". With the help of the second pronouns, the advertiser can use a participant role to communicate with the audience. For example: "Warmth to you, death to them." In the example, "you" refers to the audience who possess the fur coats, which are made from the fur of animals. The aim of the advertiser is to appeal to protecting wild animals.

The third personal pronouns can refer to a person, or an object. It commonly has richer implicature. In Chinese, “她”, “他”, “它”and“他们” are used as the third personal pronouns. While "she", "he", "it", "they" are referred as the third personal pronouns in English. For example: "In order to rebuild their home after the earthquake, we need your assistance. In order to hold up their hope for the future, we need your action." In the example, "their" refers to the people who lost their home in the earthquake.

\section{Social-Culture Factors Influencing Interpersonal Meaning in Chinese and English Public Service Advertisement}

Public service advertisement, as a kind of practical linguistic style, has unique features in vocabulary, syntax, rhetoric, etc. Its cultural connotation is quite important. The advertisement also reflects the social culture and thinking model.

Among cultures, language and thought, they have a very close relationship. They are united and interacting with each other. Language can express not only cultures, customs and way of life, but also the views of a particular culture. Language is not only reflecting expression, but also the abstraction and generalization. In the advertisement, language can express emotions, and pass information in order to influence people's behaviors and psychological activities. These functions are caused by variety of social-cultural factors.

Different Cultures. There are any cultural elements which can influence the Interpersonal Meaning in Chinese and English public service advertisement. According to Charles Mitchell's theory (2004: 174), people from different cultures process different information.

There are two types of cultures: high-context culture and low-context culture. In high-context culture, people use high context information in communications. Few words can express a complex message effectively to an in-group. So in higher context communication, choice of words are very important. The speaker who comes from a high-context culture area would not usually express his/her information exactly. But the listener can understand the meaning of what he said clearly by dealing with the context in which they are communicating. Between the speaker and the listener, the successful communication depends on the words, which are used as common knowledge and social rituals shared in one community. Chinese culture is treated as high-context culture. Thus, in the Chinese public service advertising, most of Chinese public service advertisements are expressed briefly. For example, "Save water, start from the drip." In this sentence, the advertiser does not express his information fully in words, but the audience can understand the meaning of words clearly. On the basis of common knowledge and social rituals shared in one place, the advertiser makes a strong power in educating the hearers.

Most of western cultures are low-context cultures. Low-context culture refers to the cultural tendency. It makes less extensive use of similar experiences and expectations to communicate. Much more is explained by the way of words, others by the way of context. In a low-context culture, the speaker provides the explicit codes and details in order to give mass of information to the listener and tries his/her best to state the information clearly and precisely in words. So, in the English public service advertisement, the advertiser tends to provide the audience with more details.

Different Values. There are different values like collectivism and individualism in Chinese and Western culture. Collectivism concerns with the community, people are in groups as their birth, and 
the community has a responsibility to protect its people in order to obtain the absolute loyalty. In a collectivist community, the value is similar and instructs the behavior of the individuals. China, as one of the four ancient civilizations, was founded on agriculture because of the fertile land. Chinese people like to gather together. They do not easily leave their homes. The strong emotions among people are tied by the families settled in one place, and they rely on the fertile land to live from generation to generation.

In Chinese public service advertisement, collectivism can be reflected everywhere. For example, Rebuild our homes, we are one family, 1.3 billion Chinese people give our love together. ( 重建家 园, 四海一家。13 亿双手共献我们的爱。） In the example, we can found that Chinese people attach importance to the collective strength.

Individualism does not pay much attention to the community, the bonds between individuals are loose. Western countries were founded on industry, the value of family is weak and the family structure is very simple. But western nations also have the strong sense of national identity, at the same time they also focus on pursuing freedom, liberty and personal adventure.

\section{Conclusion}

Public service advertisement is a kind of non-profitable advertisement. It is released by the media, and reveals some social problems to arouse public awareness. It aims to regulate behaviors of the public and promote some social habits. Public service advertisement plays an important role in advocating a correct value, and promoting a good social ethos. It concerns about social ideas or social issues closely related to people's daily life.

\section{References}

[1] Halliday, M.A.K: Language as Social Semiotic: The Social Interpersonal Interpretation of Language and Meaning (Edward Arnold Press, London 1978)

[2] Halliday, M.A.K. An Introduction to Functional Grammar (Edward Arnold Press, London 1985)

[3] G.W. Huang: Foreign Language Teaching, (2002) No.1, p. 34

[4] Zh.L Hu: An Introduction to Systemic Functional Grammar (Hunan Education Press, Changsha 1989)

[5] Zh.L Hu: Linguistics: A Course Book(Peking University Press, Beijing 2002)

[6] Ira Berkowitz, Vault Career Guide to Advertising (Palgrave Macmillam , New York 2004)

[7] Leech, GN. Advertising English-Advertising Linguistic Research(Longman, London 1966)

[8] Zh.Z. Li: Interpersonal Meaning in Discourse(Shanghai Foreign Language Education Press, Shanghai 2002)

[9] Y. Liu: Journal of Foreign Languages, (2004 ) No.1, p.56

[10]Martin, J.R \& Rose. D. Working with Discourse: Meaning Beyond the Clause (Continuum, London 2003) 